\title{
The psychological well-being of the Chinese elderly living in old urban areas of Hong Kong: A social perspective
}

\author{
C. W. LAM \& K. W. BOEY \\ Department of Social Work and Social Administration, The University of Hong Kong, Hong Kong, China
}

(Received 20th Fanuary 2004; accepted 2nd May 2004)

\begin{abstract}
Using the Geriatric Depression Scale-15 (GDS-15) and the short form of the General Health Questionnaire-12 (GHQ-12), this study found that the Chinese elderly who live in old urban areas of Hong Kong are at risk of suffering from poor mental health because of their relatively deprived social conditions. It was also found that the respondent's scores in the GDS-15 correlated with their social conditions, including type of housing, availability of helpers, financial status and family support. However, Chinese elderly people often avoid seeking help because of the fear of being stigmatised. There is a need for more research in the future to study their needs and problems so that social work practitioners can be well informed and culturally competent to help this disadvantaged group.
\end{abstract}

\section{Introduction}

The Chinese community in Hong Kong used to be characterized by a close-knit network of kinships that provided strong support for the elderly, but this scenario has now changed. Currently, about $11 \%$ of the elderly population (nearly 85,000) in the territory live alone (Census and Statistics Department, 2002a) and whether they can receive sufficient familial support for a quality life is doubtful. There is no pension system in Hong Kong, and those older persons who receive no support from their children and cannot cope on their own, have to rely on the Comprehensive Social Security Assistance (CSSA) (Social Welfare Department, 2004) which, however, only provides benefits to the elderly sufficient for maintaining a minimal standard of living. The problem will become increasingly serious in the future because the proportion of the population who are elderly (those aged 65 and above) will rise markedly from $11 \%$ in 2001 to $24 \%$ by 2031 (Census and Statistics Department, 2002b: 8). Given the lack of retirement protection, it is no wonder that the elderly constitute the major group of poor people in Hong Kong, with a substantial proportion (17\%) relying on CSSA and accounting for $51 \%$ of the CSSA caseload (Social Welfare Department, 2004; Census and Statistics Department, 2002b: 13).
A significant number of the elderly live in old urban areas of Hong Kong. Where the social support network has disintegrated, resulting from the migration of industries to China after the 1980s and the recent economic decline, these old urban areas have degenerated and neither better-off residents nor private developers are interested in moving to or redeveloping these regions. The government has also invested little to improve the community facilities of these areas, which are characterized by broken neighbourhoods, cramped tenements, and poor living conditions. A study has found that the older persons in these areas are of low education and do not have sufficient resources after retirement because they used to work as manual labourers, such as porters or workers in the catering and manufacturing industries, and so received meagre incomes (Mok, 1999). Since the living conditions in these areas are so undesirable, it is anticipated that those older persons living there may suffer from poor mental health.

In Hong Kong, one study found that $15 \%$ of the respondents showed signs of depression, a rate appreciably higher than the prevalence rate in the USA (Chou, Chi \& Boey, 1999). Other local studies have established that depressive symptoms are negatively associated with psychological features of the elderly, such as life satisfaction (e.g., Chi \& Boey,

Correspondence: Dr. C. W. Lam, Department of Social Work and Social Administration, The University of Hong Kong, Pokfulam, Hong Kong, China. Tel: + (852) 2859 2087. Fax: + (852) 2858 7604. E-mail: cwlam@hku.hk

ISSN 1360-7863 print/ISSN 1364-6915 online/05/02001-5 @ 2005 Taylor \& Francis Ltd

DOI: $10.1080 / 13607860412331336823$ 
1994) or self-rated health (e.g., Chan \& Leung, 1995). Some researchers have also found that the depressive symptoms of the elderly correlate significantly with their social support (Chou \& Chi, 2001a); financial strains (Chou \& Chi, 2001b), and the condition of living alone (Chou et al., 1999). Yet, in most of the research on the elderly, the problems and needs of those who live in old urban areas have not received specific attention.

The research goal of this study, therefore, was to adopt a social perspective to understand the psychological well-being of those older persons who live in old urban areas. We hypothesize that, because of their relatively deprived social conditions, the elderly living in old urban areas would exhibit evident depressive symptoms that are related to the social factors including the family network, the availability of helpers, housing conditions, and financial status. To explore whether their mental health problems were more serious because of their relatively deprived social conditions, we compared the results with those of two other groups of elderly respondents in similar studies that used the same measurements-one in Hong Kong and one in Beijing.

\section{Method}

Sampling

The data collection procedure was conducted in two old urban areas in Hong Kong. However, there was no comprehensive information on the distribution of the elderly in these two areas, and they tended to be less educated, less sociable, and more difficult to contact. Hence, purposive sampling was adopted and interviewers were asked to visit those elderly people $(n=200)$ who were the clients of two NGOs located in these areas. In addition, with the recommendations of social workers who worked in the two districts, the interviewers interviewed 266 respondents in 10 'hot spots' where elderly people in the districts usually gathered (e.g., parks, open areas near temples, etc.,). Fifteen senior-year social work students conducted the individual face-to-face interviews.

\section{Measures}

The Geriatric Depression Scale-15 (GDS-15) was developed by Sheikh and Yesavage (1986) from the GDS (Brink et al., 1982) to assess an elderly person's depressive symptoms. It was translated into Chinese and validated in Hong Kong with satisfactory reliability and validity (Lee et al., 1993; Boey \& Chiu, 1998). It has to be noted that Chinese elderly tend to over-report on depressive symptoms (see Woo et al., 1994). In order to avoid a misleadingly high prevalence rate that would be recorded if the criterion of five or above was used, and also in keeping with the criterion adopted by local studies (Boey, 2000; Boey \& Chiu, 1998), a cut-off point of eight was adopted in this research.

The General Health Questionnaire (GHQ) was developed by Goldberg (1972) for detecting nonpsychotic mental health problems in the general population. The reliability and validity of the Chinese version of the GHQ have been established (Chan \& Chan, 1983), and a 'yes-no' response format of the GHQ-12 was adopted for use with the elderly (Chi \& Boey, 1992). The recommended cut-off scores for the GHQ-12 is seven points or above (Boey \& Chiu, 1998).

The respondents were asked about their family network and whether they were living with their relatives under the same roof, or alone by themselves, and whether they had relatives living in Hong Kong. They were asked about the availability of helpers, including relatives, neighbours, or friends who could offer assistance to them when they were in trouble or faced with an emergency. They were asked about their housing e.g., private housing with independent tenancy, private housing with shared tenancy (e.g., cubicles), or public housing. The respondents were asked whether their major source of income was from their families, from their own employment or savings, or from the government's CSSA scheme. The respondents were also asked to rate their own health on a four-point scale covering their general health status, hearing, eyesight, and mobility.

\section{Results}

Excluding subjects with incomplete questionnaires and those who did not live in the local old urban areas, the effective sample consisted of 397 subjects (212 males and 185 females). The respondents' ages ranged from $60-89$, with a mean age of 73.3 . The internal consistency of the GDS-15 (Alpha $=0.83$, item total correlations ranging from 0.25 to 0.77 , $\mathrm{M}=0.55$ ) and the GHQ-12 (Alpha $=0.82$, item total correlations ranging from 0.37 to 0.76 , $\mathrm{M}=0.58$ ) were both satisfactory. Using the recommended cut-off scores for the GHQ-12 (seven or above) and the GDS-15 (eight or above), it was found that $24.7 \%$ of the respondents might be considered to have mental health problems on the GHQ and $29.7 \%$ of them might be considered to have problems of depression.

The GHQ-12 did not show any significant relationship with the social variables in this study. This is similar to the results of other studies (e.g., Boey and Chiu, 1998) finding that the GDS-15 is a more sensitive measure and accounts for greater variance than the GHQ-12 in the relationships with social support, financial status, and physical health conditions. Hence, the following discussion is mainly based on the findings of the GDS- 15 . 


\section{Family network}

It was found that those who lived alone but had relatives in Hong Kong $(n=107 ; \mathrm{M}=5.66$; $\mathrm{SD}=$ 4.04) had significantly higher depression scores than those who lived with their families $(n=160$; $\mathrm{M}=4.60 ; \mathrm{SD}=3.78)(t=2.16 ; d f=217 ; p<0.05)$. It suggested that the respondents who lived alone exhibited more depressive symptoms than those who lived with their relatives.

\section{Availability of helpers}

Table I shows that for those respondents who sought help from their families, their GDS scores ranged from 3.89 to 4.52 - significantly lower than the scores of those who did not seek help from anybody and of those who sought help from their friends.

\section{Housing}

The respondents living in private housing with independent tenancy, who had a better living environment, had significantly lower GDS-15 scores $(n=99 ; M=4.35 ; \mathrm{SD}=3.56)$ than those who lived in private housing with shared tenancy $(n=144$; $\mathrm{M}=5.85 ; \quad \mathrm{SD}=3.90), \quad(F=4.35 ; \quad d f=2, \quad 385 ;$ $p<0.05)$.

\section{Financial status}

It was found that those respondents who relied on CSSA as their major income source $(n=151$; $M=6.03 ; \quad S D=4.07$ ) had a significantly higher GDS-15 score than those who relied on their families $(n=126 ; M=4.58 ; \mathrm{SD}=3.56)$ and those who relied on their own employment or savings $(n=99 ; \mathrm{M}=$ 4.54; $\mathrm{SD}=3.85)(F=5.11 ; d f=3,386 ; p<0.05)$.

\section{Self-rated health}

The scores on the GDS-15 correlated significantly with the status of self-rated health problems with eyesight, hearing, and mobility $(r=-0.30,-0.21$, -0.17 , and -0.27 respectively) at the 0.01 level.

\section{Multiple regression analysis}

A significant relationship between the GDS-15 and social factors was identified by the multiple regression analysis, with $R^{2}=0.23$. It is worth mentioning that, in addition to self-rated health factors, housing type, the availability of helpers, and income sources also accounted for the variation in the GDS-15 scores (Table II).

\section{Discussion}

Compared with similar studies that also adopted the GDS-15, it was found that our respondents had higher mean scores than their counterparts who lived in a new town in Hong Kong (mean score $=5.23$ versus 3.33, $t$-value $=8.60, p<0.001$; Boey \& Chiu, 1998), and older people living in an urban district in Beijing (mean score $=5.23$ versus $3.9, t$-value $=$ 5.64, $p<0.001$; Boey, 2000). The comparison implies that the mental health of older persons living in old urban areas may be worse than that of their counterparts living in new towns with better

Table I. The GDS-15 scores and the availability of helpers.

\begin{tabular}{|c|c|c|c|c|c|c|}
\hline & & Nobody & $\begin{array}{c}\text { Family or } \\
\text { relatives }\end{array}$ & $\begin{array}{c}\text { Friends or } \\
\text { others }\end{array}$ & $\begin{array}{c}\text { Overall } \\
(n=397)\end{array}$ & $\begin{array}{c}F \text { value } \\
(d f=2,394) \\
p<0.005\end{array}$ \\
\hline To help in troubles & $M(S D)$ & $5.83(4.01)$ & $4.49(3.62)$ & $5.72(4.12)$ & $5.23(3.91)$ & 5.46 \\
\hline To help in an emergency & $\mathrm{M}(\mathrm{SD})$ & $5.96(3.86)$ & $4.52(3.72)$ & $5.72(4.13)$ & $5.23(3.91)$ & 6.02 \\
\hline To talk with in-depth & $M(S D)$ & $6.32(3.83)$ & $3.89(3.57)$ & $5.09(3.93)$ & $5.23(3.91)$ & 12.00 \\
\hline
\end{tabular}

*Tukey HSD post hoc at $<0.05$ level.

Table II. Multivariate analysis of factors related to GDS-15.

\begin{tabular}{|c|c|c|c|c|c|}
\hline & $\beta$ & SE $\beta$ & Beta & $t$-value & $p$ \\
\hline Self-rated health status & -1.71 & 0.39 & -0.22 & -4.35 & 0.000 \\
\hline House types ${ }^{1}$ & 1.26 & 0.38 & 0.16 & 3.36 & 0.001 \\
\hline Had people to talk with in-depth & -0.70 & 0.22 & -0.15 & -3.18 & 0.01 \\
\hline Self-rated movement & -1.15 & 0.42 & -0.14 & -2.74 & 0.01 \\
\hline Income sources ${ }^{2}$ & 0.60 & 0.22 & 0.13 & 2.79 & 0.01 \\
\hline Self-rated eyesight & -0.97 & 0.39 & -0.12 & -2.47 & 0.01 \\
\hline Self-rated hearing & -1.06 & 0.43 & -0.12 & -2.47 & 0.01 \\
\hline To help in troubles & -0.27 & 0.30 & -0.05 & -0.89 & 0.37 \\
\hline To help in emergency & -0.14 & 0.30 & -0.03 & -0.46 & 0.65 \\
\hline Alone-Relatives ( 4 groups) & -0.01 & 0.01 & -0.04 & -0.76 & 0.45 \\
\hline
\end{tabular}

${ }^{\star} R^{2}=0.23 ; F=9.71 ; d f=11,368 ; p<0.0001 .{ }^{1}$ House types: independent household, shared tenancy. ${ }^{2}$ Income sources: having own employment or savings, from family, dependent on CSSA. 
community facilities, and in China, where the traditional support from family members remains intact.

The findings of this study indicate that older persons living in old urban areas are at risk of suffering from poor mental health because of their relatively deprived social conditions. It is also confirmed that the respondents' scores on the GDS-15, apart from that relating to their health conditions, correlated with their social conditions, including type of housing, availability of helpers, and family support.

With regard to the mental health problems, it has to be noted that Chinese relied greatly on their family and friends for assistance (Cheung, 1987). Moreover, the elderly people are not vocal in expressing their needs and often avoid seeking help from mental health professionals because of the fear of being stigmatized (Casado \& Leung, 2001; Tseng, Lu \& Yin, 1995). Hence, it is a very worrying situation that family and community networks in old urban areas are disappearing, and it would not be realistic to expect older persons living in these areas to secure sufficient social support through their own efforts.

\section{Limitations of the study}

The convenience sampling approach was adopted in this study because the elderly living in old urban areas of Hong Kong are less sociable and more difficult to contact. Since it was not a stratified random sample, the conclusions drawn from this research need to be interpreted with caution and are in need of further studies for substantiation. Moreover, we were not able to determine the sensitivity and specificity of the GDS-15 by independent psychiatric diagnosis because of limited resources.

The policy implications for elderly services at this juncture are that, in addition to redeveloping the physical environment of old urban areas, the Hong Kong government should consider ways of enhancing the social network of older persons living in these areas so that the goal of 'care in the community' can be realized. It is noteworthy that those respondents who relied on the CSSA had higher scores on the GDS-15. This finding poses the question of how to make the social welfare system more effective to alleviate poverty among disadvantaged groups in the material aspect while at the same time helping their psychological well-being. The issue has become more urgent in recent years because the Hong Kong government has been trying to adopt a more strict welfare policy in order to return to a balanced budget (Chow, 2003). At the intervention level, there is no doubt that professionals can play an important role by adopting the social network approach. Central to this approach is to have adequate assessment of the elderly clients' support networks so as to understand the realities of weak support networks as well as robust ones. Equipped with this knowledge, social workers can strengthen the older people's existing networks or to create new ones which will be beneficial to their well-being (Biegel, 1985; Wenger, 1991; 1994; Andersson, 1998). In fact, little effort has been invested to understand the older persons who live alone in old urban areas. There is a need for more research in the future to study their needs, their problems and the types of network that they have, so that social worker practitioners can be well informed and culturally competent to help this disadvantaged group.

\section{References}

Andersson, L. (1998). Loneliness research and interventions: A review of the literature. Aging E Mental Health, 2 (4), 264-274.

Biegel, D. E. (1985). The application of network theory and research to the field of aging. In J. W. Sauer \& R. T. Coward (Eds.), Social support networks and the care of the elderly. Theory, research and practice. New York: Springer Publishing Company.

Boey, K. W. (2000). The use of GDS-15 among the older adults in Beijing. Clinical Gerontologist, 21, 49-60.

Boey, K. W., \& Chiu, H. F. K. (1998). Assessing psychological well-being of the Old-Old: A comparative study of GDS-15 and GHQ-12. Clinical Gerontologist, 19, 65-75.

Brink, T. L., Yesavage, J. A., Lum, O., Heersema, P., Adey, M., \& Rose, T. L. (1982). Screening tests for geriatric depression. Clinical Gerontologist, 1, 37-44.

Casado, B. L., \& Leung, P. (2001). Migratory grief and depression among elderly Chinese American immigrants. Fournal of Gerontological Social Work, 36 (1/2), 5-26.

Census and Statistics Department. (2002a). Thematic ReportOlder Persons. Hong Kong: The Printing Department.

Census and Statistics Department. (2002b). Hong Kong population projections 2002-2031. Hong Kong: The Printing Department.

Chan, A. C. M., \& Leung, E. M. F. (1995). Depression and physical health amongst the Chinese elderly in Hong Kong. Hong Kong fournal of Gerontology, 9 (1), 49-55.

Chan, D.W., \& Chan, T.S. (1983). Reliability, validity, and the structure of the General Health Questionnaire in a Chinese context. Psychological Medicine, 15, 147-155.

Cheung, F. M. (1987). Conceptualization of psychiatric illness and help-seeking behaviour among Chinese. Culture, Medicine and Psychiatry, 11, 97-106.

Chi, I., \& Boey, K. W. (1994). A mental health and social support study of the old-old in Hong Kong. Hong Kong: The University of Hong Kong.

Chi, I., \& Boey, K. W. (1992). Validation of measuring instruments of mental health status of the elderly in Hong Kong. Hong Kong: The University of Hong Kong.

Chou, K. L., \& Chi, I. (2001a). Social comparison in Chinese older adults. Aging and Mental Health, 5, 242-252.

Chou, K. L., \& Chi, I. (2001b). Financial strain and depressive symptoms in Hong Kong elderly Chinese: The moderating or mediating effect of sense of control. Aging and Mental Health, 5, 23-30.

Chou, K. L., Chi, I., \& Boey, K. W. (1999). Determinants of depressive symptoms among elderly Chinese living alone. Clinical Gerontologist, 20, 15-27.

Chow, N. W. S. (2003). New economy and new social policy in East and Southeast Asian compact, mature economies: The case of Hong Kong. Social Policy \& Administration, 37 (4), 411-422.

Goldberg, D. P. (1972). The detection of psychiatric illness by questionnaire. London: OUP. 
Lee, H. C. B., Chiu, H. F. K., Kwok, W. Y., et al. (1993). Chinese elderly and the GDS short form: A preliminary study. Clinical Gerontologist, 14, 37-42.

Mok, T. K. (1999). Poverty eradication in Hong Kong: A social development perspective. Hong Kong: Joint Publishing (H.K.) Co., Ltd. (In Chinese).

Sheik, J. I., \& Yesavage, J. A. (1986). Geriatric Depression Scale (GDS): Recent evidence and development of a shorter version. In T. L. Brink (Ed.), A guide to assessment and intervention (pp. 165-173). New York: Haworth Press.

Social Welfare Department. (2004). http://www.info.gov.hk/swd (visited on April 18, 2004).
Tseng, W. S., Lu, Q. Y., \& Yin, P. Y. (1995). Psychotherapy for the Chinese: Cultural considerations. In T. Y. Lin, W. S. Tseng \& E. K. Yeh (Eds.), Chinese societies and mental health (pp. 281294). Hong Kong: Oxford University Press.

Wenger, G. C. (1991). A network typology: From theory to practice. Fournal of Aging Studies, 5, 147-162.

Wenger, G. C. (1994). Understanding support networks in community care. Aldershot: Avebury.

Woo, J., Ho, S. C., Lau, J., Yuen, Y. K., Chiu, H., Lee, H. C., et al. (1994). The prevalence of depressive symptoms and predisposing factors in an elderly Chinese population. Acta Psychiatrica Scandinavica, 89, 8-13. 


\section{AUTHOR QUERIES}

JOURNAL ID: CAMH-41024

\section{QUERY}

QUERY

NUMBER

1

Please check volume and issue number (assumed to be March, Vol 9 No 2)

2

Please indicate where asterisk $(*)$ is to be positioned in Table I (see footnote to table) 